\title{
Open Science: a revolution in sight?
}

\author{
Bernard RENTIER \\ Université de Liège, 7 place du 20 Août, 4000 Liège, Belgium \\ brentier@ulg.ac.be
}

\begin{abstract}
- Purpose

This article aims at describing the evolution of scientific communication, largely represented by the publication process. It notes the disappearance of the traditional publication on paper and its progressive replacement by electronic publishing, a new paradigm implying radical changes in the whole mechanism. It aims also at warning the scientific community about the dangers of some new avenues and why, rather than subcontracting an essential part of its work, it must take back a full control of its production.
\end{abstract}

- Design/methodology/approach

The article reviews the emerging concepts in scholarly publication and aims to answer frequently asked questions concerning free access to scientific literature as well as to data, science and knowledge in general.

- Findings

The article provides new observations concerning the level of compliance to institutional open access mandates and the poor relevance of journal prestige for quality evaluation of research and researchers. The results of introducing an open access policy at the University of Liège are noted.

- Social implications

Open access is, for the first time in human history, an opportunity to provide free access to knowledge universally, regardless of either the wealth or the social status of the potentially interested readers. It is an essential breakthrough for developing countries.

- Value

Open access and Open Science in general must be considered as common values that should be shared freely. Free access to publicly generated knowledge should be explicitly included in universal human rights. There are still a number of obstacles hampering this goal, mostly the greed of intermediaries who persuade researchers to give their work for free, in exchange for prestige. The worldwide cause of Open Knowledge is thus a major universal issue for the $21^{\text {st }}$ Century. 


\section{Introduction}

Scholarly communication is about to change considerably driven by two major forces: 1) the outrageous escalation of the cost of access to published information in many research fields, a major incentive to the development of alternative routes and 2) the universal impact of the Internet revolution, which provides fast and inexpensive alternative routes. For a general review see Suber (2012).

Over the last two decades these two forces have successfully paved the way to the Open Access of scholarly publications (OA). Today, although these forces have been well identified and while advantages of the novel paradigms are obvious, a large proportion of researchers still publish their works in a very conservative manner. In spite of the paradoxical attitude of the scientific community - whose creativity and innovative spirit are often praised - and even more that of the assessment and evaluation bodies it creates among its own members, these forces will undoubtedly continue to progress and they will take us, sooner or later and whether we like it or not, on the path of an entirely new way of communicating among scholars and with the general public.

\section{Back to basics: why do scholars publish ?}

\section{The principle: communicate and transmit}

Scholarly publication is the act of letting the research procedures and results be known to the public, and especially to peers in science, with the aim of contributing building blocks to the progress of universal knowledge.

For centuries, research has been transmitted in print, occasionally with figures (tables, drawings, photos). Technical evolution has been slow to follow: it was problematic until recently to include films, videos, $3 \mathrm{D}$ images, etc. because of the printing limitations. Modern communication tools have emerged but remain rarely used for the same reason. Any attempt has been and still is - very expensive, however useful and sometimes necessary it can be.

Incidentally, communication at scientific meetings has always been a much more imaginative and interactive way of communicating science publicly. Such principles as open criticism and questioning are in use in these caucuses, as well as more efficient presentation tools, using colour, video and a wide range of dynamic tools.

Space scarcity has always limited the number of article pages, hence restricting the number of figures and illustrations to support the information 
and forbidding any extensive availability of raw or processed data. These limitations have always hampered the reproducibility of scientific discoveries.

\section{Quality control: the peer review process}

Since the early times of scholarly publication, the scientific revision prior to publishing has been entrusted to "peers" whose advice was considered as pertinent. Selection of peers was organised by learned societies, which used to shoulder the responsibility of publishing. Peers were requested to do the editing and/or to run a "quality control" on a voluntary basis. When private publishers took over these tasks, they perpetuated the process. In order to avoid personal conflicts, the reviewing was made anonymously most of the time but its impartiality has been often challenged (Wennerås and Wold, 1997; Link, 1998). However the most visible effects of subcontracting the publication process have been twofold: a) a mandatory abandonment by the authors of their legitimate rights and b) a spectacular escalation of the subscription prices, increasing by $400 \%$ over two decades, much higher than the overall market, due to a quasi-monopolistic situation.

\section{Internet, the turning point}

Today, electronic publishing is pervading all levels of communications. Space is no longer a limit. Access is granted to extensive raw and processed data, allowing for control and reproducibility (Van Noorden, 2015) and this has been shown to increase the citation rate (Piwowar et al., 2007). Although access is now much more wide open, reuse of results and of data is still rarely possible.

All publicly funded research deserves publication of both results and underlying data, hereby reducing the infamous rise of article retractions [ ${ }^{1}$. It would annihilate the pressure to publish only satisfying or ground-breaking results. This is also true for negative results, which are usually found to be uninteresting although their publication could spare much useless workload and avoid pointless experiments (Matosin et al., 2014).

Peer reviewing can now become easily a transparent process with documented discussions. In current times of growing transparency in all fields of social life, the unchallenged anonymous peer reviewing process is still totally devoted to selecting articles - and often authors - "worth being published" in a specific journal, leading to highly subjective choices. This selection eliminates a large part of the scientific information funded by public money, which is never published.

The tools currently available on the Web are still largely unused or misused. Scholars should take advantage of the IC technologies available to 
communicate in a more rapid, flexible and convivial manner. Open software is also too rarely used: nowadays all research tools should be open-source.

\section{A superpower: the prestige factor}

Everywhere today, selection and evaluation are based on prestige ${ }^{[2]}$ (Lehky, 2011). It is not surprising since it is and has been a dominating criterion of judgement in our societies since the earliest human social structures. Of course, prestige is partly built on real values and specific qualities (strength, intelligence, skills) but everybody knows that prestige can be very unfairly granted and poorly interpreted, particularly when it is built on indirect attribution such as through heredity, courtship or clubbing. Such a social habit is strongly linked to human processes, peer review being no exception. Prestige-based assessment of research and researchers can be misleading [3, 4] and it reinforces the dominant power of publishing companies, which can be suspected of designing strategies to improve their prestige ranking [5].

The value of a publication, if defined by its impact on the research community, is far better measured by the amount of citations it generates (excluding self and "friendly" citations) than by the reputation of the journal series or collection in which it is published, even if citations have less significance in some research fields.

Several authors (Seglen, 1997; Neuberger and Councell, 2002; PLoS Medicine editors, 2006) have called for an alternative to the so-called journal impact factor (JIF), actually a journal impact index. The recent Declaration of Research Assessment (DORA)[6], pledges to ban the JIF for inappropriate use such as individual researcher evaluation or assessment of research projects. Indeed, it is now generally admitted that using JIF for assessment of anything else than journal citation rate is a scientific nonsense and that it exacerbates prestige-based evaluation. It becomes a "prestige factor" when applied to an article or - even worse - to a researcher (Brembs et al., 2013). Although a large number of universities, research centers and funding organisations have signed the DORA, the JIF remains unfortunately the practical evaluation tool of choice, with only rare exceptions.

\section{The first step: the "green" road}

The easiest approach to free and open access to scientific literature is often referred to as 'the green road' (Harnad et al., 2004) and consists in depositing one's own scholarly work in a repository - conveniently in one's own institution - immediately upon acceptance in a "traditional" journal, before it is even published officially. The document may be accessible on line if the 
publisher permits (60\% of them do [7]) or it may remain in a closed vault from which it can be extracted only on demand and sent individually to the requester in its latest 'manuscript' version. The latter procedure is called "restricted access", it is perfectly legal as long as there are no multiple simultaneous postings and no barrier-free access.

\section{A case study: ORBi at the University of Liège}

In May 2007, the Board of Administrators at the University of Liège (ULg) voted a new regulation $\left[{ }^{8}, 9\right]$ stating that full-text articles by a ULg author or co-author published since 2002 must be deposited in the institutional repository (ORBi, for "Open Repository and Bibliography"), granting the University a complete inventory of its production in research that it had been missing much of until then.

The originality of the "Liège model" was that the mandate has been enforced by a direct and exclusive link between ORBi and all internal evaluation procedures for promotions as well as for human, financial and space resource allocations. After a short period, when depositing large numbers of documents was considered by many authors as an ancillary chore, the perceived advantages and added value have been just as effective as the mandate in ensuring that authors deposit their work. They appreciated the reports, statistics and other "goodies" provided by ORBi. Soon they discovered how much their readership had increased, as well as the number of citations of their work. Our observations are supported by others (Hitchcock, 2013).

Interestingly, this turned out to be prominent mainly for researchers in the humanities and social sciences and for those publishing in French whose audiences were significantly augmented [10].

A survey organised in 2015 revealed that $91 \%$ of the 604 responders (of which $75 \%$ chose to remain anonymous) were satisfied (57\%) or very satisfied (34\%) while $6 \%$ and $3 \%$ were unsatisfied or very unsatisfied, respectively (among these, several admitted having never published, hence never used the tool!).

The strength of the mandate is definitely responsible for the overwhelming success of ORBi. A recent study [11] by the European project "PASTEUR4OA" showed that $87 \%$ of the articles by ULg authors found in Scopus and Web of Science can be found also in ORBi while the average compliance rate in repositories with a "softer" mandate (i.e. not really enforced) is only $17 \%$, and $7 \%$ if there is no mandate at all.

All the essential features that ensure ORBi's efficiency have been summarised recently and proposed as a general recommendation for institutional repositories (Harnad, 2015). 
-Why is the compliance rate so low when the mandate is weak?

The main reason why an institutional Green OA policy fails to populate the repository is the reluctance of researchers to comply with the mandate. There are usually several objections which are easy to disprove [12], mostly:

1. Green $O A$ increases the administrative workload, charging the researcher with a subaltern duty. False. If indeed the workload can be heavy when depositing for the first time a large number of publications, it takes only five to eight minutes to input the PDF of a single article and its metadata into the repository, a negligible time when compared to that spent on writing and correcting the article itself.

2. Green $O A$ is designed to be used as an assessment tool. True, although it is not one of its primary functions, which are preservation, inventory, accessibility and high visibility. When used for an evaluation purpose, it turns out to be a much better, verifiable and fool-proof tool than the traditional list of publications provided by the researchers themselves. Moreover, it relieves the researcher from the tedious work of updating regularly their publication list.

3. Green $O A$ infringes academic freedom. False. Making the deposit is one of the many mandatory actions required by an institution from its researchers to whom it provides all the needs to perform their research. Academic freedom concerns only freedom of thought and freedom of expression in teaching, and the ability to decide which research is to be done and where to publish it. The deposit comes only after these free choices and does not influence any of them.

4. Green $O A$ infringes copyright laws. False. The legal basis of Green OA is either the consent of the copyright holder or the expiration of the copyright. The mandate obliges the researcher to make the deposit, not to make the article openly available. Why would researchers want to keep their articles behind a closed wall ? a) because it is under embargo by the publisher; b) because the researcher wants every reader to be known to themselves. (a) can be acceptable because of the signed contract between the author and the publisher, and (b) is an interesting strategy but it deprives the author(s) of a much larger audience ( $\mathrm{P}$. Thirion, personal communication).

5. Green $O A$ causes the loss of the peer reviewing process and of quality standards. False. Since the deposits follow the whole process of publication, including the quality control by peer reviewing, it does not affect this process. 
6. Green $O A$ is an obstacle to financial return on intellectual property. False. The decision to keep research results closed occurs prior to the decision to publish and the consequent commercial exploitation. The same principle applies to publication of a patent.

7. Green $O A$ deprives researchers of their royalties. False. Green OA addresses royalty-free publications where all potential income goes to the publisher. The authors publish these articles for the sake of dissemination of knowledge and/or for prestige, but not for money. Exceptions to the mandate include books or book chapters that grant royalties to their author(s). The right to benefit from royalties for books written with public support is a rarely evoked but it is an interesting issue that has to be resolved within the author's institution.

8. Green OA makes researchers run the risk of losing their work by a failure of preservation. False. For those who believe in a better chance of preservation if a text is printed on paper, this can still be done and, in the Green OA process, the article is still printed. The fear is more relevant to Gold OA (see below) for which no printed archive can be guaranteed. Depositing and harvesting allows for multiple deposit sites, lowering considerably the opportunities for a total loss.

\section{"Green $O A$ " is, in essence, temporary}

The general worldwide adoption of repositories in research performing institutions has not harmed the business of the large commercial publishers whose profits keep increasing, as they proudly claim [13]. However it seems obvious that, in the long run, Green OA can be seen as leading progressively to the disappearance of the "traditional" publication model and, possibly, of scientific publishers altogether unless they reconsider their business model and adapt to the new situation. Such an outcome would shut down Green OA itself (but not repositories, the utility of which remains high for their institutions). This is why an alternative concept of scientific communication has to be created and agreed upon, avoiding from the onset all risks of being once again captured by third parties moved by profit perspectives.

\section{The rise of "Gold"}

The "Gold road" to Open Access (Harnad et al., 2004) is the optimal - yet utopian - solution: publish and read for free. Technically, with a reasonably cheap access to Internet on both ends, it is feasible. Incidentally it corresponds to the current mode of communication through social networks. 


\section{Open peer reviewing?}

The only - strong - reason preventing the immediate implementation of totally free Gold OA is the potential loss of the peer reviewing process. However, since the latter is being operated by researchers (on a volunteer basis), publishers are left with their expertise in building worldwide reviewing panels and an alleged neutral position. Stories of biased and even partisan reviews abound, we shall not dwell on this here. But obviously, there are more and more drawbacks of the peer reviewing process, as shown by the increasing rate of article retractions, probably due to increasing publication pressure, prestige-based assessment and an overall explosive increase in the number of published documents related to a major growth of research activity. Considered by Richard Smith (former editor of the British Medical Journal (BMJ) and chief executive of the BMJ Publishing Group from 1991 to 2004) as "ineffective, largely a lottery, anti-innovatory, slow, expensive, wasteful of scientific time, inefficient, easily abused, prone to bias, unable to detect fraud and irrelevant" [14], the traditional peer review becomes hardly manageable on a large scale and, as mentioned earlier, essentially elitist, resulting in the growing accumulation of unpublished - though publicly funded - research, including unspectacular but potentially useful results. Interestingly, retractions are proportional to the JIF (Fang et al., 2011), however this may be related in part to a higher visibility of the journals.

Communication of research results should make better use of interactive reviewing methods available nowadays. It is time for the scientific community to set itself free from the obsolete constraints that it is still imposing on itself by fear of losing an old fashioned - however well intended - control.

\section{"APC-Gold OA": there is no such thing as a free lunch}

Facing the tide of Open Access, the major publishing companies and many professional societies have started to adapt their offer, proposing a derivative of the "Gold route" that they wisely and purposely but misleadingly call "Gold OA": an option to publish in immediate open access while paying a fee for it, namely the "article processing charge" (APC). A rapid calculation shows that, in order for the publisher to preserve with "APC-Gold OA" the profit of the traditional publication scheme, pricing must increase (Harnad, 2007). It is now reaching an average $2,500 €$ per article, ranging from 250 to $6,000 €$ and according to the current trend, it is expected to rise more.

Besides the often underestimated - though obvious - authors' conflict of interest when they pay to publish, it appears clearly that prices are becoming proportional to the publisher's prestige. In such conditions, the APC-Gold OA, a very appealing and practical paradigm, will become even more antidemocratic than the traditional publication scheme could be. In the past, 
everybody had the opportunity, with a good quality paper (or a good introduction) to publish in the most prestigious journals in their fields of competence, even if their universities could not afford to buy them. Now everyone will be able to read the scientific literature but only those with access to significant funding will publish in prestigious collections.

The Max Planck Digital Library has proposed an attempt in the direction of an "all to APC-Gold OA" in 2015 [15]. However it is primarily based on the preservation of publishers' business model as well as their prestige ranking and it appears to many as a very unsafe agreement, unable to solve both the cost issue and the peer review shortcomings.

The trouble with "APC-Gold OA" is that there is absolutely no guarantee of pricing stability. As long as the mission remains in the control of multinational for-profit companies, it is reasonable to predict that prices will keep increasing and will do so proportionate to the publisher's prestige, a value these companies are going to keep cultivating as long as it influences researchers' choices and evaluators' judgment.

There is also a new perversion of the transition to open access: the new "hybrid Gold OA", sometimes referred to as "double dipping", i.e. a double payment (Pinfield et al., 2015). Indeed, the principle is that the article is published in the traditional way, the reader or library pays for the subscription but the authors are also required to pay if they wish to make their article immediately open access.

As Björn Brembs puts it [16]: " of the $\sim U S \$ 10$ billion we collectively pay publishers annually world-wide to hide publicly funded research behind paywalls, we already know that only between 20o-8oo million go towards actua costs. The rest goes towards profits ( $3-4$ billion) and paywalls or other inefficiencies ( $\sim 5$ billion). What do we get for overpaying such services by about 98\%? We get a literature that essentially lacks every basic functionality we've come to expect from any digital object ».

\section{Imposter publishers}

Yet another drawback of APC-Gold OA is the rapid emergence of cheap uncontrolled OA journals run by ill-named "predatory" publishers (the term "predatory" applies better to the big "traditional" publishing companies who sell prestige at outrageous prices) better called "imposter" publishers. They manage to appear legitimate, luring researchers through spamming into submitting their work or entering fake editorial boards, using a false or nonexistent peer review process, neglecting digital preservation, "high jacking" real journals and sometimes even collecting money from authors without publishing their work. Such journals have been blacklisted [17]. However listings are dangerous in that they might include respectable publishers whose 
activities may be questionable but not guilty. They may also lack the expected reasoning on why OA journals are in the list $\left[{ }^{18}, 19\right]$. A reasonably good approach of OA journals evaluation is that of the Directory of Open Access Journals (DOAJ) $\left.{ }^{20}\right]$. It should be added that a reputed publisher has been using fraudulent practices as well $\left[{ }^{21},{ }^{22}\right]$.

\section{Beyond Open Access}

Science must go back to cooperative rather than competitive processes and researchers must take advantage of the Internet revolution to do so [23, 24]. The reading time will surely remain competitive - and even more so because of the growing scientific production [25] - but the reviewing process must stop being reserved to a relatively small group of self-proclaimed elite which, ipso facto, are no longer "peers" ${ }^{[26]}$.

Although strongly disputed by some [27], it seems that open and transparent peer reviewing is the key [28]. Lately, The Self Journal of Science [29], RIO [30] and a few others $\left[{ }^{31}, 3^{2}, 33\right]$ have launched attempts in this direction.

Open sharing of research data is the obvious next step [34] if crucial information is not to be lost [35] but requires concerted institutional management (Whyte and Tedds, 2011).

Finally, full openness, searchability, reproducibility and peer-control of research ("Open Science") can only be reached if the research software used is free, open and completely transparent ${ }^{[36]}$.

The entire research production process must be revisited and made widely open at every step, in the spirit of what is referred to as Open Science (Pontika et al., 2015).

All these steps require sensitisation and mobilisation of the research community worldwide, which is at a turning point and facing diverging options. It is high time for academic institutions to define clear policies (Swan, 2012). Hopefully these will finally converge towards a common goal and allow scholarship to take back its full responsibilities as the knowledge provider the ultimate public service.

\section{Acknowledgements}

The author wishes to thank Mr. Paul Thirion, Head librarian at the University of Liège (ULg), and all members of his team, for developing, setting up and running the institutional repository, ORBi. 


\section{References}

Brembs, B., Button, K., and Munafò, M. (2013), "Deep impact: unintended consequences of journal rank". Frontiers in Human Neuroscience, 7, 291, available at http://dx.doi.org/10.3389/fnhum.2013.00291 (accessed 5 June 2016).

Fang, F.C., Casadevall, A. and Morrison, R.P. (2011), "Retracted science and the retraction index". Infect. Immun. 79, 3855-3859, also available at http://iai.asm.org/content/79/10/3855.full (accessed 5 June 2016)

Harnad, S. (2007), The Green Road to Open Access: A Leveraged Transition. In: Anna Gacs. The Culture of Periodicals from the Perspective of the Electronic Age. L'Harmattan. 99-106, available at:

http://eprints.soton.ac.uk/265753/ (accessed 5 June 2016).

Harnad, S., Brody, T., Vallieres, F., Carr, L., Hitchcock, S., Gingras, Y, Oppenheim, C., Stamerjohanns, H., \& Hilf, E. (2004), "The Access/Impact Problem and the Green and Gold Roads to Open Access", http://dx.doi.org/10.1016/j.serrev.2004.09.013, Serials Review 30 (4), also available at: http://www.nature.com/nature/focus/accessdebate/21.html (accessed 5 June 2016).

Harnad, Stevan (2015) Open Access: What, Where, When, How and Why. In: Ethics, Science, Technology, and Engineering: An International Resource eds. J. Britt Holbrook \& Carl Mitcham, (2nd of Encyclopedia of Science, Technology, and Ethics, Farmington Hills MI: MacMillan Reference), also available at http://eprints.soton.ac.uk/361704/1/ESTEarticle-OA-Harnad.pdf (accessed 5 June 2016).

Hitchcock, S. (2013), “The effect of open access and downloads ('hits') on citation impact: a bibliography of studies". Open Citation Project, http:/ /opcit.eprints.org/oacitation-biblio.html (accessed 5 June 2016).

Lehky, S. (2011), "Peer evaluation and selection systems. Adaptation and maladaptation of individuals and groups through peer review", Google Books, available at:

https://books.google.be/books?id=SW_6Q_I5R-

cC\&printsec $=$ frontcover\&dq=inauthor:\%22Serge + Lehky\%22\&hl=fr\&sa $=$ X\&ve $\mathrm{d}=$ oahUKEwi4xpeI973LAhWBkQ8KHSqPD8UQ6AEICjAA\#v=onepage\&q\&f= false (accessed 5 June 2016).

Link, A. (1998), "US and Non-US Submissions. An Analysis of Reviewer Bias". JAMA， 280(3):246-247. doi:10.1001/jama.280.3.246, available at: 
http://jama.jamanetwork.com/article.aspx?articleid=187751 (accessed 5 June 2016).

Matosin, N., Franck, E. and Newell, K.A. (2014), "Negativity towards negative results: a discussion of the disconnect between scientific worth and scientific culture" Dis Model Mech. 7(2): 171-173. (doi: 10.1242/dmm.015123), available at:

http://www.ncbi.nlm.nih.gov/pmc/articles/PMC3917235/\# ffn_sectitle.ht ml (accessed 5 June 2016).

Matthews, D. (2016), "High rejection rates by journals 'pointless'. Analysis suggests higher selectivity fails to increase journals' impact factors". Times Higher Education. https://www.timeshighereducation.com/news/highrejection-rates-by-journals-pointless (accessed 5 June 2016).

Neuberger, J. and Counsell, C. (2002), "Impact factors: uses and abuses". European Journal of Gastroenterology \& Hepatology, 14 (3):209-211, available at: http://www.ncbi.nlm.nih.gov/pubmed/11953682 (accessed 5 June 2016).

Pinfield, S., Salter, J., \& Bath, P. A. (2015). "The "total cost of publication" in a hybrid open-access environment: Institutional approaches to funding journal article-processing charges in combination with subscriptions". Journal of the Association for Information Science and Technology, (Early view). doi:10.1002/asi.23446, available at: http://eprints.whiterose.ac.uk/83525/ (accessed 5 June 2016)

Piwowar H.A., Day R.S., and Fridsma D.B. (2007), "Sharing detailed research data is associated with increased citation rate". PLOS One, 2(3):e308, available at:

http://journals.plos.org/plosone/article?id=10.1371/journal.pone.0000308 (accessed 5 June 2016).

PLOS Medicine Editors (2006), "The impact factor game". PLOS Medicine, 3(6):e291, available at:

http://journals.plos.org/plosmedicine/article?id=10.1371/journal.pmed.0030 291 (accessed 5 June 2016).

Pontika, N., Knoth, P., Cancellieri, M. and Pearce, S. (2015), "Fostering Open Science to research using a taxonomy and an eLearning portal". i-KNOW'15Proceedings of the 15th International Conference on Knowledge Technologies and Data-driven Business, Article No. 11, ACM New York, NY, USA, available at:

https://doc-00-20docs.googleusercontent.com/docs/securesc/haoro937gcuc 7 l7deffksulhg.h $7 \mathrm{~m}$ bp1/sq1ounatsavblpihi1q2k079lo7vgcgk/145915200000o/089253382335534 
June 2016).

Renaville F. (2013), "A mandate for Open Access: The University of Liège (ULg) and ULg Library". Ex Libris Initiatives Blog, available at: http://initiatives.exlibrisgroup.com/2013/05/a-mandate-for-open-accessuniversity-of.html (accessed 5 June 2016).

Seglen P.O. (1997), "Why the impact factor of journals should not be used for evaluating research". British Medical Journal, 314(7079):497, available at: http://www.bmj.com/content/314/7079/497.1 on "a 14-day free trial” or at: http://www.ncbi.nlm.nih.gov/pmc/articles/PMC2126010/pdf/9056804.pdf in open access (both accessed 5 June 2016)

Suber P. (2012), Open access, the book, MIT Press, Essential knowledge series, available at: http://bit.ly/oa-book (accessed 5 June 2016).

Swan, A. (2010), "The Open Access citation advantage: Studies and results to date”. University of Southampton. Retrieved from:

http://eprints.soton.ac.uk/268516/ (accessed 5 June 2016).

Swan, A. (2012), "Policy guidelines for the development and promotion of open access". UNESCO, Paris, $76 \mathrm{pp}$., available at:

http://unesdoc.unesco.org/images/0021/002158/215863e.pdf (accessed 5 June 2016).

Van Noorden, R. (2015), "Sluggish data sharing hampers reproducibility effort”. Nature doi:10.1038/nature.2015.17694, available at:

http://www.nature.com/news/sluggish-data-sharing-hampers-

reproducibility-effort-1.17694_(accessed 5 June 2016).

Wagner, B. (2010), "Open access citation advantage: An annotated bibliography”. Issues in Science and Technology Librarianship, 6o, available at: http://www.istl.org/10-winter/article2.html_(accessed 5 June 2016).

Wennerås, C. and Wold, A. (1997), "Nepotism and sexism in peer-review". Nature 387, 341-343, doi:10.1038/387341ao, available (behind a paywall) at : http://www.nature.com/nature/journal/v387/n6631/full/387341ao.html and in open access at: http://www.cs.utexas.edu/users/mckinley/notes/wwnature-1997.pdf (accessed 5 June 2016).

Whyte, A. and Tedds, J. (2011), "Making the Case for Research Data Management”. DCC Briefing Papers. Edinburgh: Digital Curation Centre, available at: http://www.dcc.ac.uk/resources/briefing-papers (accessed 5 June 2016). 


\section{Websites and Newspaper articles (all accessed 2 April 2016)}

${ }^{1}$ http://retractionwatch.com

${ }^{2}$ http://legacy.earlham.edu/ peters/writing/jbiol.htm

3 http://occamstypewriter.org/scurry/2015/12/04/jolly-good-fellows-royalsociety-publishes-journal-citation-distributions/

4 https://bernardrentier.wordpress.com/2015/12/31/denouncing-theimposter-factor/

5 https://www.timeshighereducation.com/news/high-rejection-rates-byjournals-pointless

6 http://www.ascb.org/dora/

7 http://www.sherpa.ac.uk/romeo/PDFandIR.php?la=en

8 http://orbi.ulg.ac.be/project?locale $=$ en\&id $=102$

9 http://orbi.ulg.ac.be/project?locale=en\&id=103

10 http://orbi.ulg.ac.be/stats?\&level=general\&page=downviews-series$\underline{\mathrm{ulg} \& \mathrm{tab}=3}$

${ }^{11}$ http://www.pasteur40a.eu/sites/pasteur4oa/files/deliverables/PASTEUR4 OA\%20Work\%20Package\%203\%20Report\%20final\%2010\%20March\%20201 5.pdf, see p.27.

12 http://legacy.earlham.edu/ peters/writing/jbiol.htm

13http://www.relx.com/investorcentre/reports\%202007/Documents/2014/re lxgroup_ar_2014.pdf

${ }^{14}$ https://www.timeshighereducation.com/content/the-peer-review-drugsdont-work

${ }^{15}$ http://pubman.mpdl.mpg.de/pubman/item/escidoc:2148961:7/component/e scidoc:2149096/MPDL_OA-Transition_White_Paper.pdf

16 http://bjoern.brembs.net/2016/05/why-havent-we-already-canceled-allsubscriptions/

17 https://scholarlyoa.com/2016/01/05/bealls-list-of-predatory-publishers2016/

18 http://citesandinsights.info/civ14i4.pdf

19 http://citesandinsights.info/civ16i3.pdf 
20 https://doaj.org/faq\#predatory

${ }^{21}$ http://www.the-scientist.com/?articles.view/articleNo/27383/title/Elsevierpublished-6-fake-journals/

22 http://www.nature.com/nm/journal/v15/n6/full/nm0609-598a.html

${ }^{23}$ https://www.digital-science.com/blog/guest/collective-collaborativecomplementary-that-is-what-makes-the-oan-unique/

${ }^{24}$ https://www.force11.org/about/manifesto

25 http://www.cdnsciencepub.com/blog/21st-century-science-overload.aspx

26 http://www.sciencemag.org/news/2014/12/does-journal-peer-reviewmiss-best-and-brightest

27 http://www.nature.com/nature/peerreview/debate/natureo4991.html

28 http://blog.f10ooresearch.com/2014/05/21/what-is-open-peer-review/

29 http://www.sjscience.org

30 http://riojournal.com/about

${ }^{31}$ http://www.openscholar.org.uk/open-peer-review/

$3^{2}$ http://rsos.royalsocietypublishing.org/content/open-peer-review-royalsociety-open-science

33 http://p2pfoundation.net/Open_Peer_Review

34

http://ec.europa.eu/research/participants/data/ref/h2020/grants_manual/h i/oa_pilot/h2020-hi-oa-pilot-guide_en.pdf

35 http://www.upi.com/Science_News/2013/12/19/80-percent-of-scientificdata-from-publicly-funded-research-is-lost-within-twodecades/8781387477327/\#ixzz3PYcUxswu

${ }^{6}$ https://www.fsf.org/about/ 